\title{
Vertebral hyperostosis and diabetes mellitus: a case-control study
}

\author{
A Daragon, O Mejiad, P Czernichow, J P Louvel, O Vittecoq, A Durr, X Le Loët
}

\begin{abstract}
Objective-To compare glucose metabolism in patients with vertebral hyperostosis (VH), with that in control patients. Methods-We studied 50 patients aged 60 years or more who had VH according to Resnick's criteria, and 50 control patients without VH, matched for sex, age, weight and height. Plasma glucose was evaluated before and 120 minutes after ingestion of $75 \mathrm{~g}$ glucose. World Health Organisation criteria for diabetes mellitus (DM) were used. Radiographs of the pelvis and thoracic and lumbar spine were performed and read blind by two physicians. Results-Statistical analysis showed no difference between cases and control patients for prevalence of $D M$, and plasma glucose at 0 and 120 minutes.

Conclusion-These data suggest that glucoregulation in patients with VH does not differ from that in matched controls.
\end{abstract}

(Ann Rheum Dis 1995; 54: 375-378)

Vertebral hyperostosis (VH) was described by Forestier and Rotes-Querol in 1950 as 'senile ankylosis hyperostosis of the spine'. ${ }^{1}$ It occurs mostly in the elderly, and is characterised by bony bridges between vertebrae leading to ankylosing. Usually painless, this disease involves mainly the thoracic spine, and to a lesser degree the lumbar and cervical spine, without reduction of the discal space. The prevalence of $\mathrm{VH}$ increases with age; it is uncommon before 40 years. One study of 12858 people aged more than 40 found a prevalence of $\mathrm{VH}$ of $2.5 \%$ in women and $3.5 \%$ in men. ${ }^{2}$ In France, the prevalence was estimated at $5 \%$ after 60 years of age. ${ }^{3}$

Because the prevalence of $\mathrm{VH}$ has been reported to be high among elderly diabetic subjects $(21-40 \%),{ }^{45}$ and because diabetes mellitus (DM) was found in $23-40 \%$ of patients with $\mathrm{VH}^{6}{ }^{6}$ a relationship between $\mathrm{VH}$ and DM has been suggested. However, obesity has also been implicated, ${ }^{2}$ and the relationship between DM and $\mathrm{VH}$ remains controversial. ${ }^{4}$

The aim of the study was to determine if there is an association between $\mathrm{VH}$ and abnormalities of glucose tolerance, using a case-control design.

\section{Patients and methods}

Over a 24 month period, all patients admitted to hospital in our rheumatology department were systematically screened for $\mathrm{VH}$, to identify cases and controls. These patients had been admitted with various diseases: joint diseases $(11 \%)$, spinal diseases $(13 \%)$, other rheumatic diseases $(24 \%)$, cancer $(20 \%)$, and non-rheumatic diseases (32\%) which included cardiac $(3.5 \%)$, psychiatric $(3 \%)$, neurological $(2 \%)$, digestive $(2 \%)$, and pulmonary $(1 \%)$ diseases.

For each patient, we recorded the intake of non-steroidal anti-inflammatory drugs (NSAID) and diuretics, and the delay between admission and the time at which the glucose tolerance test was performed.

\section{CASES}

Cases were patients who fulfilled Resnick's criteria for VH (so called 'diffuse idiopathic skeletal hyperostosis' (DISH)) ${ }^{8}$ :

1) Presence of flowing calcification and ossification along the anterolateral aspect of at least four contiguous vertebral bodies, with or without associated localised pointed excrescences at the intervening vertebral bodyintervertebral disc junction.

2) Presence of relative preservation of intervertebral disc height in the involved vertebral segment and the absence of extensive radiographic changes of degenerative disc disease, including vacuum phenomena and vertebral body marginal sclerosis.

3) Absence of apophyseal joint ankylosis and sacroiliac joint erosion, sclerosis or intraarticular osseous fusion.

Over the 24 month period, 2480 patients were screened to provide 50 cases $(25$ male), all older than 60 years.

\section{SELECTION OF CONTROL PATIENTS}

Fifty control subjects were recruited from the same screened population. They were matched for sex, for age ( \pm five years) and for weight/ height index.

For the weight/height index, we used Lorenz's index to evaluate the ideal weight ${ }^{9}$ :

$$
\begin{aligned}
\text { Males: } \mathrm{IW} & =\mathrm{H}-100-\{(\mathrm{H}-150) / 4\} \\
\text { Females: } \mathrm{IW} & =\mathrm{H}-100-\{(\mathrm{H}-150) / 2 \cdot 5\}
\end{aligned}
$$

where $\mathrm{IW}=$ ideal weight $(\mathrm{kg})$ and $\mathrm{H}=$ height (cm). This permitted classification of subjects into four classes:

Class 1: W (measured weight) $<90 \%$ IW

Class 2: $90 \%$ IW $<W \leqslant 110 \%$ IW

Class 3: $110 \%$ IW $<W<120 \%$ IW

Class 4: $W \geqslant 120 \% \mathrm{IW}$. 
Cases and controls were matched within these classes.

NON-INCLUSION AND EXCLUSION CRITERIA In addition to exclusion criteria related to radiographic analysis and nutritional status (described below), patients (with or without $\mathrm{VH}$ ) were not included in the study if steroids were administered for at least one month during the past year, glucose infusion was performed since their admission to hospital, duration of their stay in hospital was short (less than four days), ankylosing spondylitis was suspected on clinical symptoms, only one or two bony bridge(s) were found in radiographs, or a disease likely to be associated with glucose intolerance was suspected.

Known DM was not a criterion for exclusion from the study, for cases or for controls.

\section{RADIOGRAPHY}

Recent radiographs (less than one year) of the thoracic and lumbar spine (anteroposterior and lateral views) and the pelvis were obtained. At the end of the study, radiographs were examined, separately and blind, by two observers experienced in osteoarticular reading. If they failed to agree and could not reach a consensus, the case was excluded from further study.

GLUCOSE TOLERANCE

A $75 \mathrm{~g}$ oral glucose tolerance test was performed after three days of steady state normal regimen. Morning fasting blood samples were obtained before (t0) and two hours after ingestion of glucose ( $\mathrm{t} 2$ ).

National Diabetes Data Group of the NIH criteria (=WHO criteria) were used. ${ }^{10} \mathrm{We}$ compared $\mathrm{VH}$ and controls for diabetes mellitus, impaired glucose tolerance, and serum glucose at t0 and $\mathrm{t} 2$.

Patients (potential cases and controls) unable to take a sufficient diet of calories and carbohydrates for the three days before the test were not included.

STATISTICS

Chi-square test (or Fischer test when appropriate) for qualitative parameters, and Mann-Whitney test for quantitative parameters were used to compare cases and control patients. Probabilities $<0.05$ were considered significant.

\section{Results}

Table 1 shows details of the two matched groups, with no differences between them.

GLUCOSE TOLERANCE TEST

No DM had been recognised before the glucose tolerance test (table 2) was performed. The test revealed six patients in each group to have DM. Twenty eight patients had impaired
Table 1 Clinical characteristics of patients studied. No significant differences between groups

\begin{tabular}{lcc}
\hline & $\begin{array}{c}\text { Hyperostosis } \\
(n=50)\end{array}$ & $\begin{array}{c}\text { Controls } \\
(n=50)\end{array}$ \\
\hline Sex $(\mathrm{M} / \mathrm{F})$ & $25 / 25$ & $25 / 25$ \\
Age (yr) & & \\
$\quad 60-69$ & 15 & 15 \\
$70-79$ & 22 & 20 \\
$>80$ & 13 & 15 \\
Weight $(\mathrm{kg}) \dagger$ & $69(14)$ & $68(14)$ \\
Height (cm)t & $162(10)$ & $160(10)$ \\
Overweight index & & \\
1 & 4 & 4 \\
2 & 14 & 14 \\
3 & 9 & 9 \\
4 & 23 & 23 \\
\hline
\end{tabular}

†Mean (SD). $\ddagger 1$ : Weight (W) $<90 \%$ ideal weight (IW) $; 2: 90 \%$ IW $<$ W $\leqslant 110 \% \quad$ IW; $3: 110 \%$ IW $<$ W $<120 \%$ IW; 4 $\mathrm{W} \geqslant 120 \% \mathrm{IW}$.

Table 2 Results of the oral glucose tolerance test

\begin{tabular}{lccl}
\hline & $\begin{array}{c}\text { Hyperostosis } \\
(n=50)\end{array}$ & $\begin{array}{c}\text { Controls } \\
(n=50)\end{array}$ & $p$ \\
\hline $\begin{array}{l}\text { Diabetics (No) } \\
\begin{array}{l}\text { Impaired glucose } \\
\text { tolerance (No) }\end{array}\end{array}$ & 6 & 6 & $\mathrm{NS}$ \\
$\begin{array}{l}\text { Normal glucose } \\
\text { tolerance (No) }\end{array}$ & 32 & 16 & $\mathrm{NS}$ \\
$\begin{array}{l}\text { Blood glucose (mmol/1) } \dagger \\
\text { t0 (fasting) }\end{array}$ & $5.3(1)$ & $5.1(1)$ & 0.77 (NS) \\
t2 (at 120 min) & $8.0(3)$ & $8.3(3)$ & 0.20 (NS) \\
\hline
\end{tabular}

† Mean (SD). NS = not significant.

glucose tolerance, 12 in the VH group, and 16 in the control group. No difference was found between the two groups for any parameter.

The delay between admission and glucose tolerance test time was 12 (SD 10) days in the cases, and 13 (SD 10) days in the control group (NS).

\section{WEIGHT/HEIGHT INDEX}

Weight/height index was not significantly different between $\mathrm{VH}$ (median $=116$ ) and controls (median =115), but was slightly greater among diabetic (median $=122$ ) than among non-diabetic subjects (median $=116$ ) (not significant). The figure shows individual results for the patients with DM; there was no

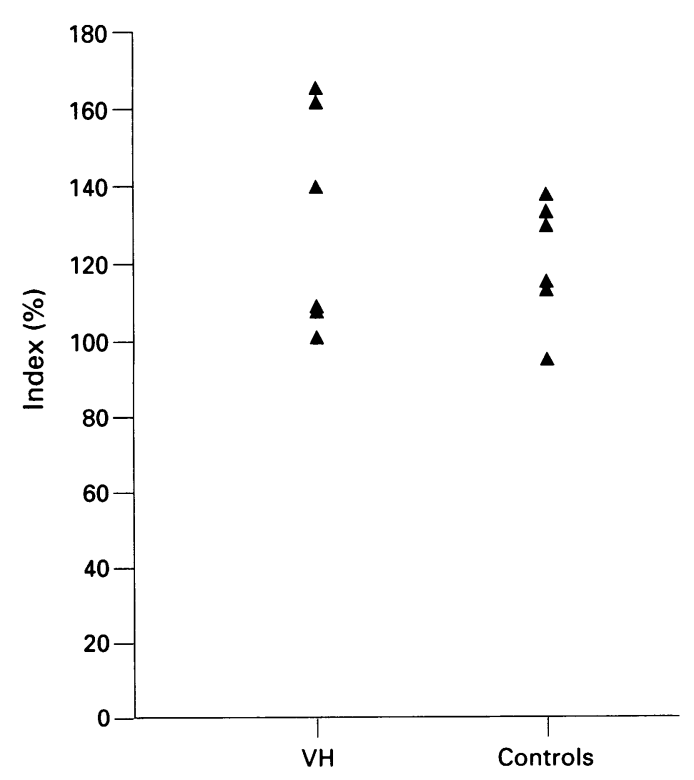

Individual values of the weight/height index among diabetic subjects (six with vertebral hyperostosis $(V H)$ and six controls). 
significant difference between cases and controls.

NON-STEROIDAL ANTI-INFLAMMATORY DRUGS Eighteen cases $(36 \%)$ were treated by NSAID, compared with nine (18\%) patients in the control group $(p<0.05)$. No statistical difference was found for the glucose tolerance test between patients receiving $(n=27)$ or not receiving $(n=73)$ NSAID therapy.

\section{DIURETICS}

Thirteen cases (26\%) and 10 control patients $(20 \%)$ were treated with diuretics during the study (difference not significant).

\section{ASSOCIATED DISEASES}

Osteoporosis, defined by one or more vertebral crush fractures, was found to be more frequent in control patients $(\mathrm{n}=8,16 \%)$ than in cases $(\mathrm{n}=2,4 \%) \quad(\mathrm{p}<0.05)$. None was diabetic. Inflammatory arthropathies were more frequent among $\mathrm{VH}$ patients ( $\mathrm{n}=10,20 \%)$ than in controls $(\mathrm{n}=4,8 \%)$ (NS); they included rheumatoid arthritis $(n=5)$, polymyalgia rheumatica $(n=2)$, chondrocalcinosis $(n=4)$, and arthralgia of undetermined origin $(n=3)$. Non-rheumatic diseases were present in $38 \%$ of cases and $26 \%$ of controls (NS).

\section{Discussion}

In this study no difference in glucoregulation was found between cases and matched controls, even though we used the oral glucose tolerance test recommended by the WHO for the recognition of diabetic patients. Thus, on the basis of our results, there is no relationship between VH and DM.

The number of patients was chosen to have a $90 \%$ chance of detecting a $10-30 \%$ difference of DM between the two groups, as predicted from the literature. In fact, the frequency of DM was low $(12 \%)$ and strictly identical in both groups.

The equal number of males and females with VH was due to chance, as patients were recruited consecutively. This distribution is at variance with that found in other studies, in which the prevalence of $\mathrm{VH}$ was greater in men than in women. ${ }^{2}{ }^{3}$

Our sample may not reflect the general population, as it was composed of patients with various diseases, mainly rheumatic. However, $30 \%$ of the hospital inpatient population had a variety of diseases such as cardiac, psychiatric, neurological, and digestive. The distribution of the diseases between our two groups was not different, except for osteoporosis which was more frequent in the control group. It is possible that, in common with osteoarthritis, ${ }^{11}$ osteoporosis is less frequent among $\mathrm{VH}$ patients, but the number of patients may have been too small to permit firm conclusions. Nevertheless, the results were not influenced by this difference, as no osteoporotic patient was diabetic.
In order to account for possible influences of drugs on glucoregulation, we sought differences attributable to diuretics, but found none. It has been suggested also that NSAIDs are able to alter glycoregulation. ${ }^{12}$ Many of our patients $(27 \%)$ were treated with NSAIDs because these drugs are commonly used for rheumatic diseases. Cases received them more often than controls, perhaps because inflammatory diseases were more frequent than in the control group (though not significantly so). Had NSAIDs had an effect, an increase in the number of patients with DM would have been observed in the VH group, but this was not the case. Patients taking steroid drugs were excluded from the study.

An association between $\mathrm{VH}$ and $\mathrm{DM}$ has been suggested, ${ }^{13}$ and DM has been reported in $23-42 \%$ of $\mathrm{VH}$ patients. ${ }^{67}$ However, the criteria used to define DM were different in those studies. As the prevalence of DM after age 60 is not well established (specifically so in France), and as factors such as overweight are associated with $\mathrm{DM}^{2}$ it is necessary to compare the $\mathrm{VH}$ patients with weight-height matched controls.

In 1966, Julkunen et $a l^{4}$ found more $\mathrm{VH}$ among 510 diabetic patients than in controls, but only for the age group 60-69; only fasting blood glucose was measured, and criteria for DM were not described in detail. Lequesne, in a more recent retrospective study, ${ }^{6}$ found that $\mathrm{DM}$ was more frequent among cases with $\mathrm{VH}$ and that $\mathrm{VH}$ was more frequent among diabetics; but the groups comprising this study were each recruited in a different hospital unit and, in common with the patients studied by Julkunen $e t$ al, the influence of weight was not taken into account.

In another study, Julkunen et al compared 94 males and 70 females with controls matched for sex, age, occupation, and place of residence, and performed an oral glucose tolerance test. ${ }^{2}$ They found a difference only for women aged 40-59, with plasma glucose concentrations significantly greater than in controls. Furthermore, the weight/height index was greater among patients with $\mathrm{VH}$, and a relationship between glucose tolerance and overweight was observed. Overweight was thus likely to have been responsible for the difference observed in women. In our study, $64 \%$ cases were above the ideal weight, and $46 \%$ were class 4 overweight. This proportion is higher than that of a previous study in which we found $25 \%$ of patients with lumbar degenerative disease were overweight. ${ }^{14}$ Such a result stresses the necessity to compare study groups with weight-height matched controls.

Recently, Troillet et al ${ }^{15}$ studied 25 patients with $\mathrm{VH}$ and 25 control patients matched for age, sex, and body mass index; they found no difference between the two groups in serum glucose, glycated haemoglobin and insulin.

We may conclude that glucoregulation, evaluated by glucose tolerance test, did not differ between VH patients and sex, age, and weight-height matched control patients. As our population was selected, the validity of extrapolating our results to the general 
population need to be confirmed by a population based study. Nevertheless, we have shown that DM is probably not an aetiological factor for $\mathrm{VH}$, but weight may well be.

The authors wish to thank Dr N Moore for his help in editing the manuscript.

1 Forestier J, Rotes-Querol J. Hyperostose ankylosante vertébrale sénile. Rev Rhum Mal Osteoartic 1950; 10 525-34.

2 Julkunen $\mathrm{H}$, Heinonen $\mathrm{O}$, Pyorola K. Hyperostosis of the spine in an adult population. Ann Rheum Dis 1971; 30 605-12.

3 Vignon G, Durant J, Pansu D, Bertrand J N, Truchot R. $\mathrm{La}$ spondylorhéostose ou hyperostose ankylosante vertébrale sénile. Rev Rhum Mal Osteoartic 1961; 28: vertebrale.

4 Julkunen H, Karava R, Viljanen V. Hyperostosis of the spine in diabetes mellitus and acromegaly. Diabetologia 1966; 2:

5 Hajkova Z, Streda A, Skrha F. Hyperostotic spondylosis and diabetes mellitus. Ann Rheum Dis 1965; 24: 536-43.

6 Lequesne M, Cassan P, Nallet J, Ryckewaert A, de Sèze S. Hyperostose vertébrale et diabète sucré. Rev Rhum Mal Osteoartic 1970; 37: 281-6.
7 Henrard J C, Benett P H. Etude épidémiologique de l'hyperostose vertébrale. Enquête dans une population adulte d'Indiens d'Amérique. Rev Rhum Mal Osteoartic 1973; 40: 581-91.

8 Resnick D, Niwayama G. Radiographic and pathologic features of spinal involvement in diffuse idiopathic seletal hyperostosis. Radiology 1976; 119: 559-68.

9 Herpin D, Guillard O, Piriou A, et al. Effets comparés du pindolol et de l'aténolol sur la tension artérielle et le bilan lipidique en cas d'hypertension artérielle légère à modérée. Ann Med Interne 1988; 139: 484-7.

10 Ito C, Mito K, Hara H. Review of criteria for diagnosis of diabetes mellitus based on results of follow-up study. Diabetes 1983; 32: 343-51.

11 Dequeker J. The relationship between osteoporosis and osteoarthritis. Clinics in Rheumatic Diseases 1985; 11: 271-96.

12 Vinceneux $P$, Lubetski D, Kahn $M$ F. Quel antiinflammatoire et quel antalgique choisir chez le diabetique? fourn Annu Diabetol Hotel Dieu Paris: 1978; 281-93.

13 Boulet P, Serre H, Mirouze J. Le rachis diabétique. Semaine des Hopitaux de Paris 1954; 30: 2392-410.

14 Daragon A, Czernichow P, Courtois $\mathrm{H}$, et al. La glycémie à jeun et post prandiale chez les sujets atteints de cruralgie et de sciatique. Rev Rhum 1985; 52: 7-11.

15 Troillet N, Gerster J C. Metabolic alterations in patients with diffuse idiopathic skeletal hyperostosis: a prospective controlled study in twenty five patients. Rev Rhum (English edn) 1993; 60: 239-44. 